\title{
Development of Learning Analytics Dashboard based on Moodle Learning Management System
}

\author{
Ong Kiat Xin ${ }^{1}$, Dalbir Singh ${ }^{2}$ \\ Center for Software Technology and Management (SOFTAM) \\ Faculty of Information Science and Technology, Universiti Kebangsaan Malaysia \\ Acronyms Acceptable, Bangi, Malaysia
}

\begin{abstract}
Digitalization catalyzes drastic changes to a particular subject or area. Digitalization is an operational structure transformation process, such as in the educational domain. Digitalization in the academic field has brought the classroom to the users' fingertips with the prevalence of elearning applications, learning management systems, etc. However, with the increasing number of digital learning platform users, educators find it hard to monitor their students' progress. Analytics that analyze data generated from the usage pattern of the users contribute to giving the educators an insight regarding the performance of their students. With that, they can apply early intervention and modification of their delivery method to suit the students' needs and, at the same time, increase the quality of the content. This study illustrates the development of a learning analytics dashboard that can improve learning outcomes for educators and students.
\end{abstract} moodle

Keywords-Learning analytics; learning management system;

\section{INTRODUCTION}

Learning Management System (LMS) is a software application developed for the administration, tracking, reporting, and delivery of educational courses and contents [1]. There are various LMS(s) to choose from in the market; for example, Moodle is the most widely used LMS. LMS utilizes the internet as an extension of learning, allowing users to access the content anytime and anywhere. With more learning activities conducted online, obtaining relevant and accurate data from these activities has become more important for educators to monitor their students' performance [2]. However, some existing analytics dashboards available on the market do not present accurate and relevant data for educators to understand their students' performance [3]. Purposely, an analytics dashboard is expected to indicate the attainment of the learning outcomes by the learners and triggers continuous improvement in the delivery and assessment method. Therefore, it is vital to develop a dashboard that displays accurate and relevant data that could provide insight for learners, educators and relevant stakeholders, which could eventually improve the overall learning process.

In this study, the analytics dashboard development approach has been proposed. Firstly, the back-end of the analytics dashboard has been designed and developed so that accurate and relevant data can be displayed on the dashboard. Secondly, a straightforward and easy-to-use interface has been created to allow users to read data easily. The analytics dashboard has been designed to fulfil the need in order to obtain relevant and meaningful data from a data source so that educators can better understand their students' performance [4]. There are three (3) main sections that focus on (a) review relevant studies and related analytics dashboards, (b) analytics dashboard requirement, and (c) proposed analytics dashboard design that constructs the proposed learning analytics dashboard as the contribution of study which outlines relevant data visualization strategy.

\section{REVIEW OF RELEVANT STUDIES AND RELATED ANALYTICS DASHBOARDS}

This section discusses relevant previous studies and related analytics dashboards. It comprises the following three (3) sections that focus on Moodle LMS, data analytics, and a review of a corresponding analytics dashboard. It aims to provide a fundamental understanding of the related area and prepares for a review of data visualization and dashboard design in the subsequent section.

\section{A. Moodle LMS}

Moodle LMS is a web-based system specifically developed to complement traditional learning methods that allow users to attend courses, submit assignments, and many more online. Moodle LMS is an open-source learning management system developed using PHP programming language and was first released in 2002. With the increasing demand and usage of online learning, Moodle now has more than 278 million registered users in 2021 [5].

Moodle LMS is designed to support teaching and learning with over ten (10) years of development guided by social constructionist pedagogy [6]. Moodle LMS has a simple interface with drag-and-drop features and well-documented resources along with ongoing usability improvements. Moodle LMS has very high flexibility and scalability that can be customized to support the needs of both small classes and large organizations.

\section{B. Data Analytics for Moodle LMS}

Data analytics is the process of analyzing raw data to conclude the information contained in them. Valuable insights can be extracted from data analytics to assist users in planning and taking actions [7]. Data analytics can be divided into four categories: descriptive analytics, diagnostic analytics, predictive analytics, and prescriptive analytics [8]. Descriptive analytics contributes to showing the value of measured metrics and what had happened in a specified period. Descriptive analytics process raw data from data sources to give valuable 
insights into the past. Implementing descriptive analytics in the learning analytics dashboard would allow the educators to understand their students' performance trends and identify any issues. Diagnostic analytics is the next step of complexity in data analytics. While assessing the descriptive data, diagnostic, analytical tools allow the analyst to drill down and isolate the root cause of a problem. Diagnostic analytics gives in-depth insights into a particular problem on why the problem occurred.

Predictive analytics is advanced analytics that brings many advantages, such as sophisticated analysis based on machines or deep learning. It is a proactive approach that enables predictions. Predictive analytics contributes to providing a forecast of what is likely to happen. Predictive analytics utilizes descriptive and diagnostic analytics findings to detect clusters and exceptions and predict future trends. Predictive analytics is a valuable tool for forecasting. Prescriptive analytics is sophisticated analytics that utilizes machine learning and algorithms to prescribe a possible action that can be taken to eliminate a future problem.

Therefore, four types of analytics can be implemented into the analytics dashboard for Moodle LMS. Most commercial solutions available in Moodle LMS are descriptive analytics [6]. Moodle LMS provides various built-in reporting tools based on log data; however, they are primarily illustrative. Third-party developers can develop learning analytics dashboards that emphasize diagnostic and prescriptive analytics to understand the cause of events and figure out solutions to improve learning outcomes.

\section{Review of Relevant Analytics Dashboard for Moodle LMS}

It has become a challenge for developers to design an analytics dashboard that suits the needs in the educational domain to process the data generated by online learning activities [2]. Each analytics dashboard has features that do not necessarily fulfil every user's requirement [9]. The design of the analytics dashboard can be varied, depending on the implementation of the developer. Providing a simple easy-toread dashboard is very important.

In our study, three (3) analytics dashboards have been chosen: Piwik Analytics, Blocks: Progress Bar, and Blocks: Analytics Graph. These analytics dashboards were selected to be most actively updated in the Moodle LMS plug-in library [6]. Fig. 1, Fig. 2, and Fig. 3 shows three (3) examples of the analytics dashboard available as Moodle LMS plug-in. As shown in Fig. 1, Piwik Analytics provides reporting in the form of a comparative table. Data such as page views, bounce rate, and average generation time are recording to provide an overview for the user to understand their contents hit rate.

As shown in Fig. 2, Blocks: Progress Bar is a reporting tool that reports on the students' progress. The users can gather information regarding the progression of the students.

As shown in Fig. 3, Blocks: Analytics Graph shows the distribution of the hits of the course content in the form of a line graph. Similar to Piwik Analytics in Fig. 1, the contents accessed rate of the students shown in the chart that allows the user to develop an overview of the course contents access rate.

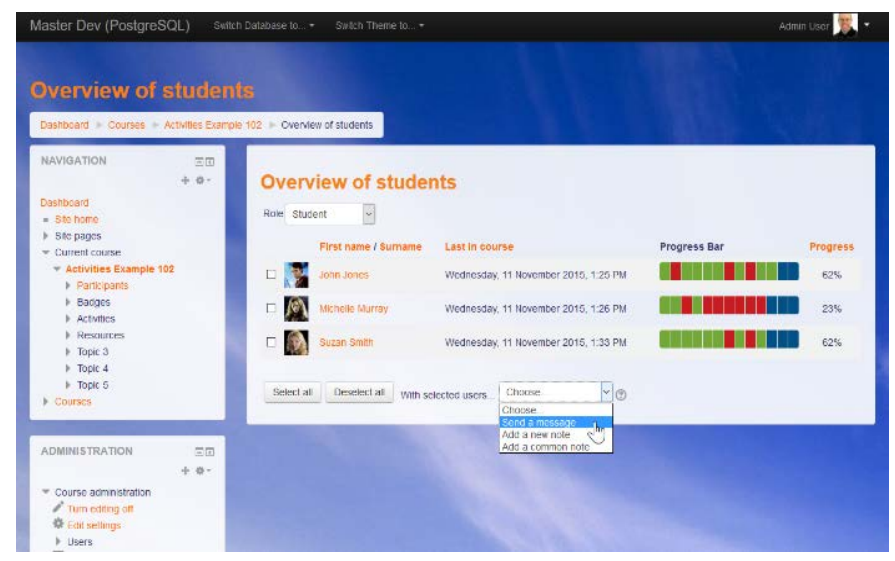

Fig. 1. Piwik Analytics

\section{PIWIK}

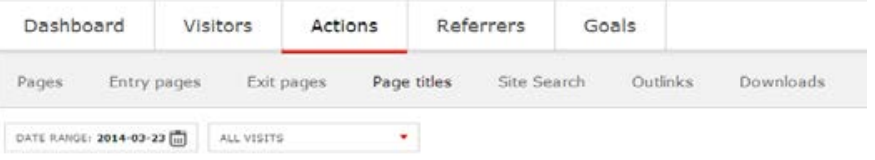

Page titles

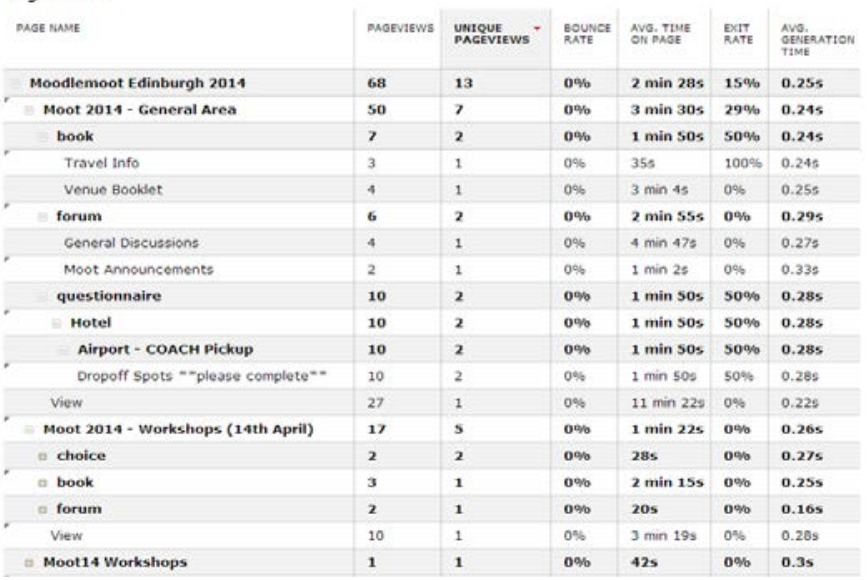

Fig. 2. Blocks: Progress Bar.
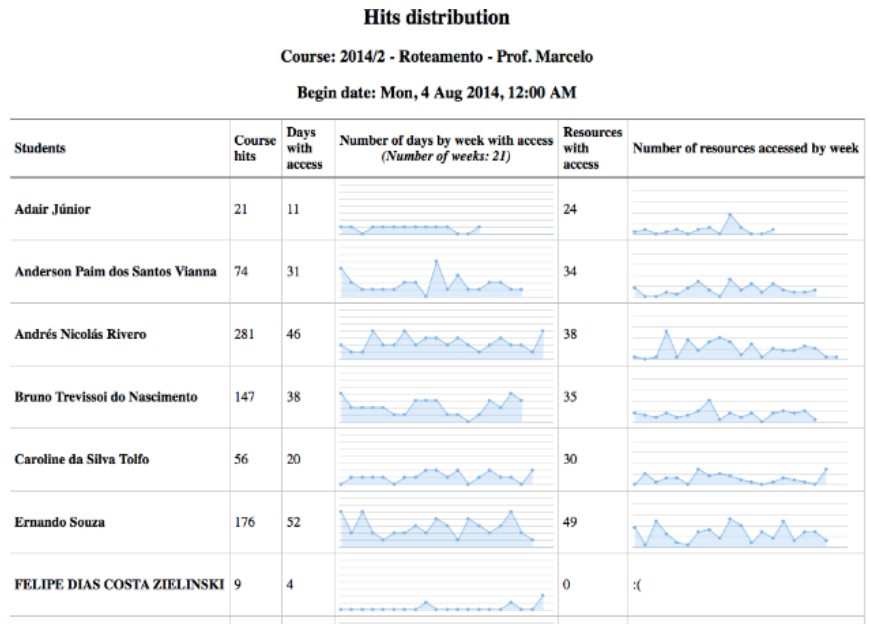

Fig. 3. Blocks: Analytics Graph.

Based on the comparative analysis of the common features available in these dashboards, a comparison table is tabulated, 
as shown in Table I. The finding based on Table I reveals that assignment progress and learning progress can be considered as common features between these analytics dashboards. Indirectly, assignment progress and learning progress are essential features for any learning analytics dashboard [10].

TABLE I. COMPARISON BETWEEN EXISTING DASHBOARDS

\begin{tabular}{|l|l|l|l|}
\hline $\begin{array}{l}\text { Features } \\
\text { (Measuring Metrics) }\end{array}$ & $\begin{array}{l}\text { Piwik } \\
\text { Analytics }\end{array}$ & $\begin{array}{l}\text { Blocks: } \\
\text { Progress Bar }\end{array}$ & $\begin{array}{l}\text { Blocks: } \\
\text { Analytics Graph }\end{array}$ \\
\hline User active time & Yes & No & Yes \\
\hline Assignment Progress & No & Yes & Yes \\
\hline Learning Progress & No & Yes & Yes \\
\hline Marks & No & No & Yes \\
\hline $\begin{array}{l}\text { Assignments } \\
\text { Submission }\end{array}$ & No & No & Yes \\
\hline Contents Hit Count & Yes & No & No \\
\hline
\end{tabular}

\section{LEARNING ANALYTICS DASHBOARD REQUIREMENTS}

User requirements have to be fulfilled to achieve the objective of developing the analytics dashboard. The primary user base of the analytics dashboard focuses on the educators who use a learning management system such as Moodle as part of their teaching medium. The analytics dashboard will become a tool for them to monitor their student's progress quickly and efficiently.

Various types of assessment can be implemented in LMS [11]. Our study revealed that assignments handouts using LMS are common usages of LMS in modern learning. Tracking a student's assignment has become more important for educators to keep track of their students. Knowing the performance of their students allows educators to decide on how to improve the outcome.

Learning progress reporting is also an essential element in a learning analytics dashboard. A learning analytics dashboard that has both the educator-facing dashboard and student-facing dashboard is an ideal implementation [10]. The educator-facing dashboard allows the educators to understand the progress report of their students and helps the educators develop an overview of their courses and identify students with low performance. On the other hand, the students-facing dashboard allows the students to keep track of their progress, which helps them increase their self-awareness of their performance.

The learning analytics dashboard is designed to extract data from the data source and convert the data into meaningful data visualization. The data visualization allows the users to understand the information that is shown in the analytics better. Key data visualization charts in the analytics dashboard include marks of students' assignments, quizzes, attendance, project marks, and, most importantly, their progress in terms of learning outcomes.

The system model of the analytics dashboard only involved three main entities: Moodle LMS, the analytics dashboard, and the users. Data is generated continuously from online activities held in Moodle LMS, such as online quizzes and online assignments. The information is then stored in the Moodle LMS server. The data is then downloaded and converted into a readable format of the analytics dashboard. Once the data is uploaded to the analytics dashboard, the back-end system of the analytics dashboard will automatically convert the data into data visualization, such as a table, line charts, and bar charts. The users can interact with the dashboard after the data visualization.

\section{Proposed Learning AnAlytics DashboARd Design}

The design specification of the analytics dashboard is influenced by the objective and the current design trend. The design specification of a system that will be developed is important because the users' workflow is affected by design. The analytics dashboard is created as a web application using Python and Dash framework. This approach allows the developer to better focus on data visualization as the Dash framework in Python is specialized in data visualization. Besides, developing the system as a web application is more productive as users do not need to install the software; they can view the dashboard using any web browser. Fig. 4 shows an example of an analytics dashboard design that can be implemented.

The design of the analytics dashboard has to produce data visualization with simplicity so that the users can read the data accordingly when there is a lot of data. Implementing personalized options and interaction in the dashboard is preferable for a better user experience [12]. The back-end of the analytics dashboard is designed so that the data obtained from the data source can be converted into data visualization. One of the approaches our study has revealed is that the analytics dashboard can be developed using the Dash framework in Python. The end product will be a web-based analytics dashboard that can be accessed using any web browser. The main component of the analytics dashboard is the interface. The dashboard will display all the data visualization in a scrollable manner. The users can glance through all of the data quickly. Fig. 5 shows the name list of all the students in a certain course in a table that can be implemented in the dashboard. The table provides a simple overview of the student's performance in a specific course.

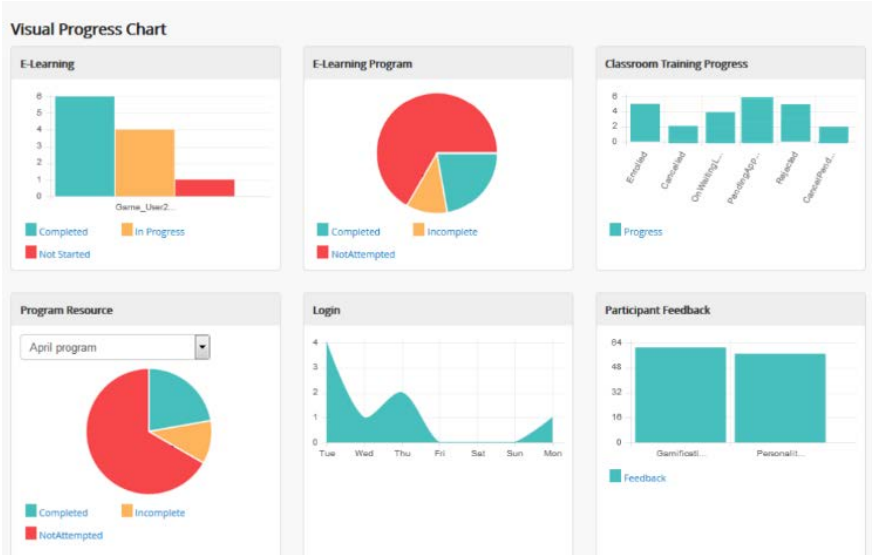

Fig. 4. A Design Example of an Analytics Dashboard. 


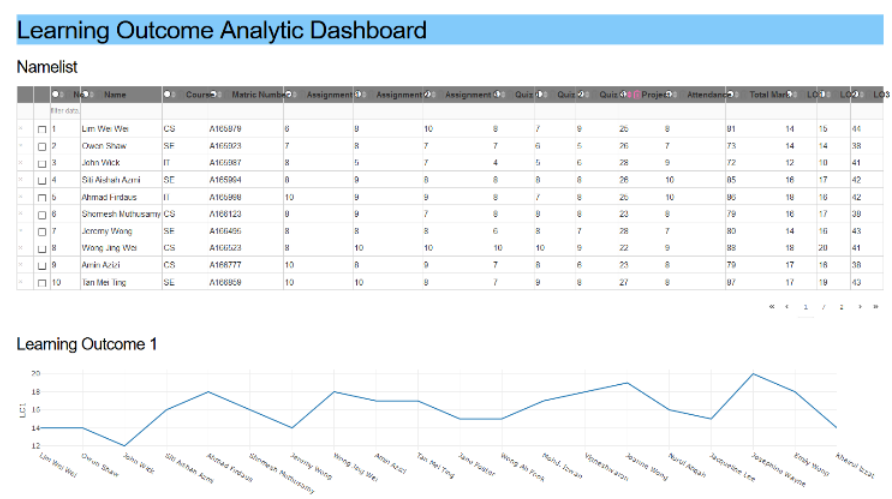

Leaming Outcome 2

Fig. 5. The Interface of the Analytics Dashboard.

Moreover, the analytics dashboard also shows the students' achievement in terms of learning outcomes in a line graph. This type of data visualization provides a simple explanation of the performance of the student. The users can know the highest performer as well as the lowest. Fig. 6 shows the line graphs shown in the analytics dashboard.

The other data visualization available in the analytics dashboard includes the bar chart. The bar charts show the individual mark of each student in terms of assignments, quizzes, attendance, and their total marks. Fig. 7 and 8 show the bar charts that are shown in the analytics dashboard. The bar charts allow the users to read the progress trend of each student in each measuring metric.

Other than data visualization, analytics dashboards that allow users to interact will provide a better user experience. Fig. 9 shows the selected students in the table. The users can pick whichever student they want in the table on top of the analytics dashboard. The chosen students will be highlighted in Fig. 10, 11 and 12. This provides the users with convenience when reading the data.

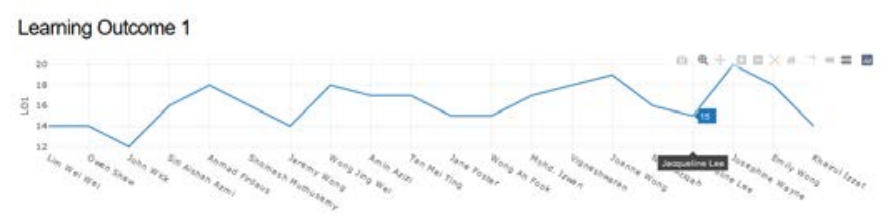

Leaming Outcome 2
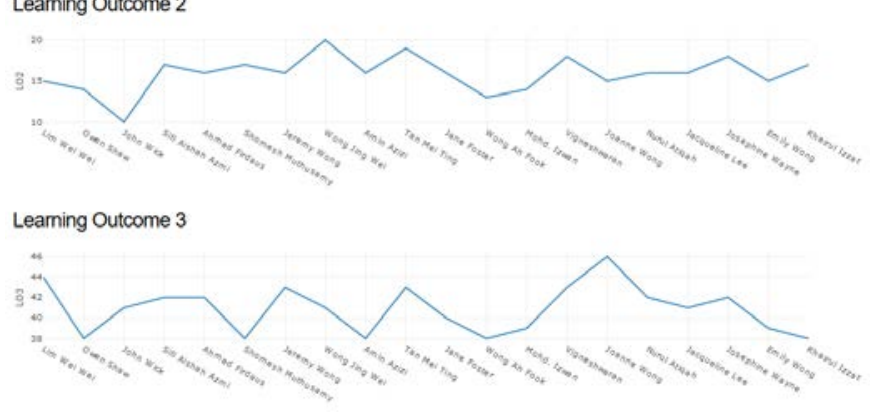

Fig. 6. Example Line Graphs.
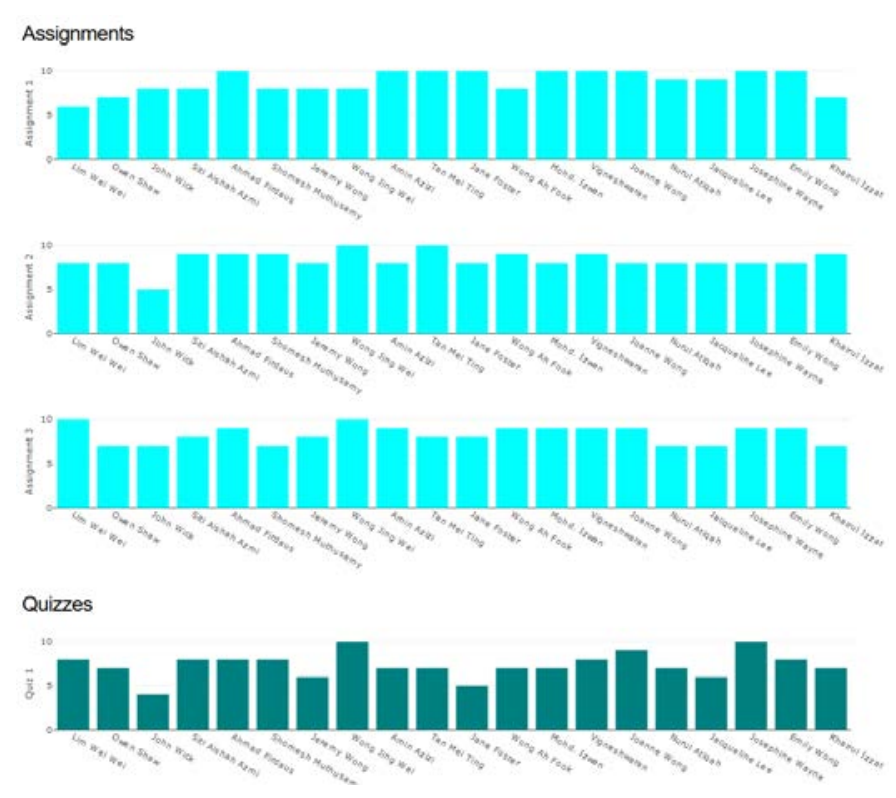

Fig. 7. Example Bar Charts 1.
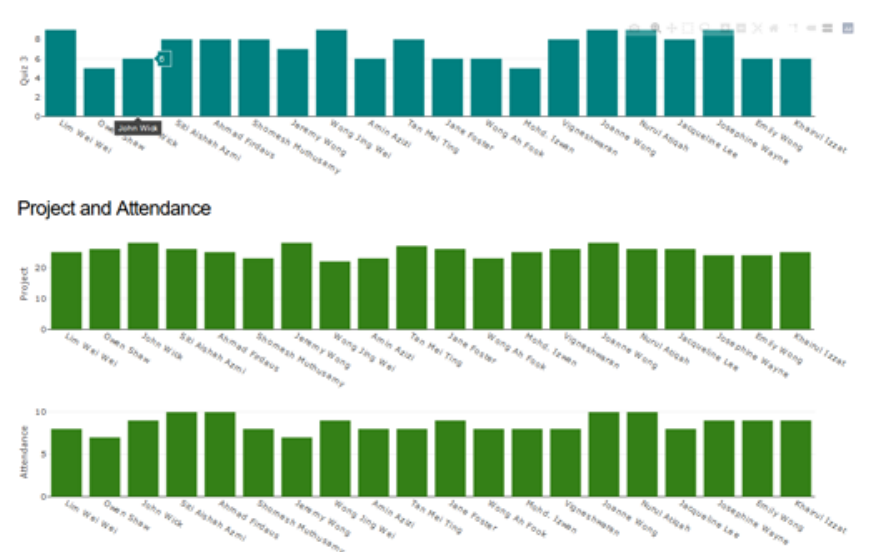

Total Mark

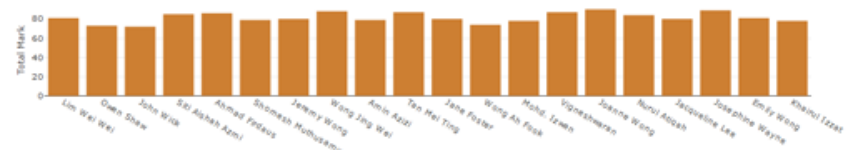

Fig. 8. Example Bar Charts 2.

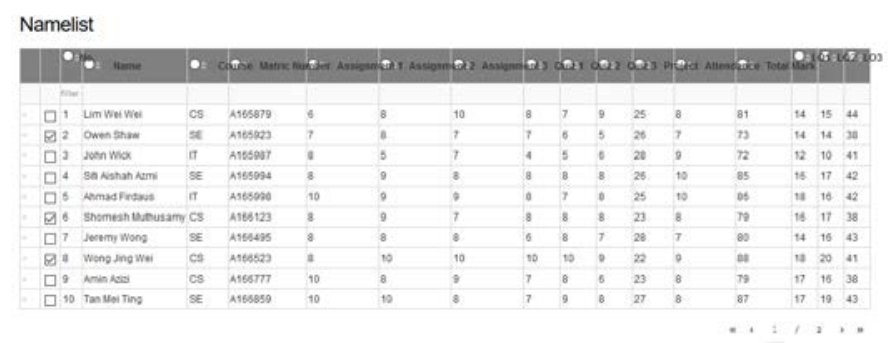

Fig. 9. Selected Students. 


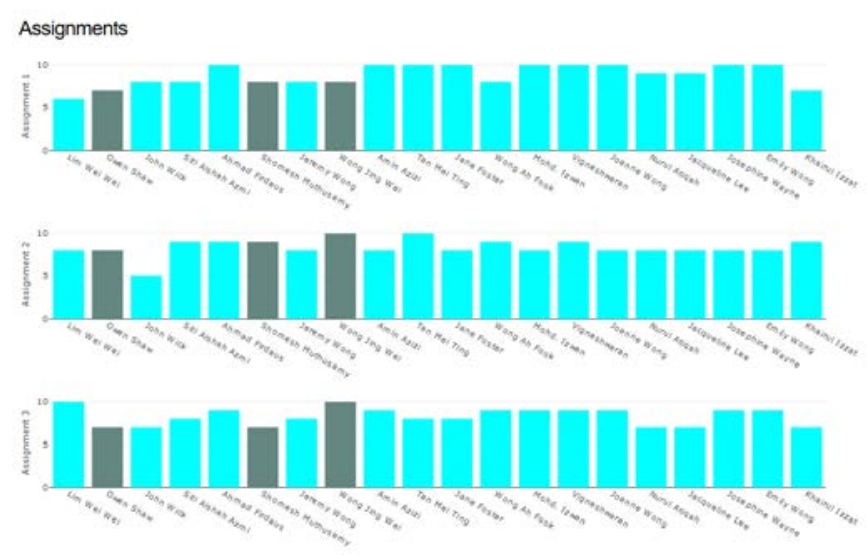

Fig. 10. Highlighted Students in Assignment.

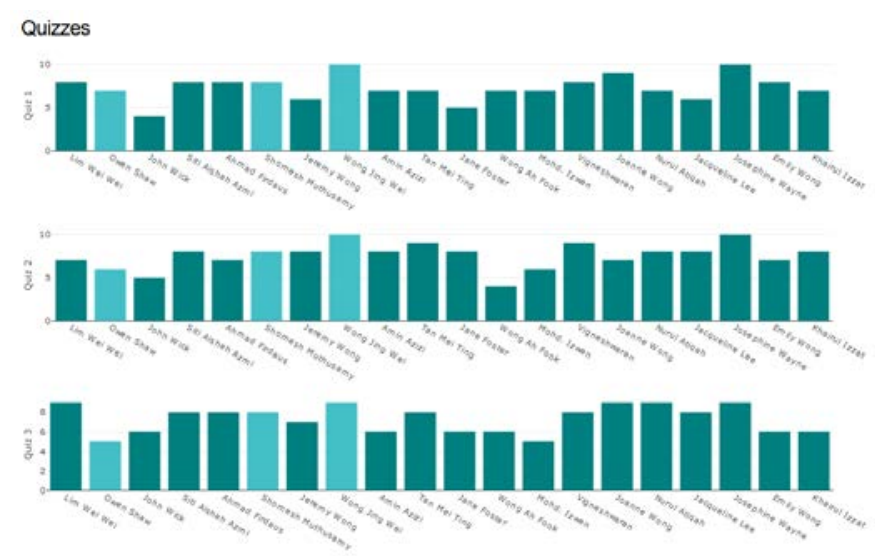

Fig. 11. Highlighted Students in Quizzes.

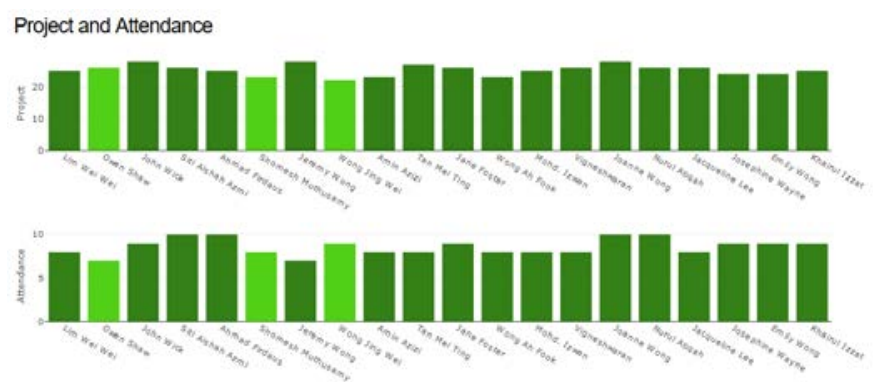

Total Mark

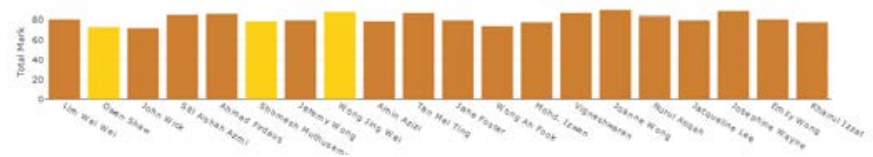

Fig. 12. Highlighted Students in Project and Attendance.

\section{CONCLUSION}

In conclusion, the study has provided an extensive view of the approach when developing a learning analytics dashboard that can be implemented within Moodle LMS. A well-designed analytics dashboard will allow educators to understand better the data collected by the LMS through online learning activities [13]. Meaningful insights obtained from the analytics will help educators to understand the performance of their students [14] [15] [16]. Descriptive analytics will allow educators to monitor the performance of their students in a specific period. In contrast, more complex analytics such as diagnostic and prescriptive analytics will explain the cause of events and actions to improve the situations. Thus, such implication has the potential for future research work which could benefit educators and learners [17] [18] [19] [20] [21]. Furthermore, studies investigating novel and innovative methods for measuring learning outcomes attainment, especially for online learning during COVID-19 pandemic era, have caught the attention of various researchers [22] [23]. Thus, this triggers the development of a learning analytics dashboard, particularly for Moodle, as it is the most widely used LMS.

\section{ACKNOWLEDGMENT}

The researchers would like to express their highest gratitude towards Universiti Kebangsaan Malaysia's research grant: GGP-2019-026.

\section{REFERENCES}

[1] A. K. Alhazmi and A. A. Rahman, "Why LMS failed to support student learning in higher education institutions," IEEE Symposium. ELearning, E-Management E-Services, pp. 1-5, October 2012.

[2] H. Aldowah, H. Al-Samarraie, and W. M. Fauzy, "Educational data mining and learning analytics for 21st century higher education: A review and synthesis," Telematics and Informatics, vol. 37, pp. 13-49, April 2019.

[3] O. Viberg, M. Hatakka, O. Bälter, and A. Mavroudi, "The current landscape of learning analytics in higher education," Computers in Human Behavior, vol. 89, pp. 98-110, December 2018.

[4] N.-S. Chen, C. Yin, P. Isaias, and J. Psotka, "Educational big data: extracting meaning from data for smart education," Interactive Learning Environments, vol. 28, no. 2, pp. 142-147, February 2020.

[5] Moodle, "Moodle Statistics," Moodle, 2021. [Online]. Available: https://stats.moodle.org/. [Accessed: 25-July-2021].

[6] Moodle, "Moodle Documentation," Moodle, 2020. [Online]. Available: https://docs.moodle.org/39/en/About_Moodle. [Accessed: 11-Aug2020].

[7] G. Elia, G. Polimeno, G. Solazzo, and G. Passiante, "A multi-dimension framework for value creation through Big Data," Industrial Marketing Management, vol. 20, pp. 508-522, October 2020.

[8] N. Nistor and Á. Hernández-Garcíac, "What types of data are used in learning analytics? An overview of six cases," Computers in Human Behavior, vol. 89, pp. 335-338, December 2018.

[9] D. Gašević, S. Dawson, T. Rogers, and D. Gasevic, "Learning analytics should not promote one size fits all: The effects of instructional conditions in predicting academic success," The Internet and Higher Education, vol. 28, pp. 68-84, January 2016.

[10] H. Deng et al., "PerformanceVis: Visual analytics of student performance data from an introductory chemistry course," Visual Informatics, vol. 3, no. 4, pp. 166-176, December 2019.

[11] C. Schumacher and D. Ifenthaler, "Features students really expect from learning analytics," Computers in Human Behavior, vol. 78, pp. 397407, January 2018.

[12] D. Azcona, I. H. Hsiao, and A. F. Smeaton, "Personalizing computer science education by leveraging multimodal learning analytics," IEEE Frontiers in Education Conference (FIE), pp. 1-9, October 2018.

[13] N. R. Aljohani, A. Daud, R. A. Abbasi, J. S. Alowibdi, M. Basheri, and M. A. Aslam, "An integrated framework for course adapted student learning analytics dashboard," Computers in Human Behavior, vol. 92, pp. 679-690, March 2019.

[14] E. A. C. Olga I. Vaganova, Zhanna V. Smirnova, Ekaterina V. Vezetiu, Maxim M. Kutepov, "Assessment tools in e-learning Moodle," International Journal of Advanced Trends in Computer Science and Engineering, vol. 9, pp. 2488-2492, May 2020. 
[15] A. J. P. D. and R. N. V. Glendell R. Jadraque, "Algorithmic Analytics for Outcomes-based Tertiary Education Performance Assessment," International Journal of Advanced Trends in Computer Science and Engineering., vol. 9, pp. 766-773, February 2020.

[16] A. M. and H. A. Sami Hachmoud, Adil Hachmoud, "Analysis of Students Online Learning Behavior in a Pedagogical Model combining Blended Learning and Competency Based Approach," International Journal of Advanced Trends in Computer Science and Engineering, vol. 8, pp. 3389-3395, December 2019.

[17] N. Alias, Z. Zakariah, N. Z. Ismail, and M. N. A. Aziz, "E-Learning Successful Elements for Higher Learning Institution in Malaysia," Procedia - Social and Behavioral Sciences, vol. 67, November 2011, pp. 484-489, November 2012.

[18] M. M. Mohd Salihan Ab Rahman, Nazlena Mohamad Ali, "Comelgetz Prototype in Learning Prayers among Children," Asia-Pacific Journal of Information Technology and Multimedia, vol. 6, pp. 115-125, June 2017.

[19] N. A. M. Z. Mercy Trinovianti Mulyadi, "Mmorpg Game Framework based on Learning Style for Learning Computer Netwoking," AsiaPacific Journal of Information Technology and Multimedia, vol. 8, pp. 63-77, June 2019.
[20] N. A. A. Salyani Osman, Noraidah Sahari@Ashaari, Nor Azan Mat Zin, Ratna Zuarni Ramli, "Courseware using Cognitive Apprenticeship Strategy," Asia-Pacific Journal of Information Technology and Multimedia, vol. 5, pp. 1-18, December 2016.

[21] T. S. M. T. W. Hairulliza Mohd. Judi, Hanimastura Hashim, "Knowledge Sharing Driving Factors in Technical Vocational Education and Training Institute using Content Analysis," Asia-Pacific Journal of Information Technology and Multimedia, vol. 7, pp. 11-28, December 2018.

[22] M. Diena Dwidienawati, Sri Bramatoro Abdinagoro, David Tjahjana, Dyah Gandasari, "Forced Shifting to e-Learning during the COVID-19 Outbreak: Information Quality, System Quality, Service Quality, and Goal Orientation influence to e-Learning Satisfaction and Perceived Performance," International Journal of Advanced Trends in Computer Science and Engineering, vol. 9, pp. 1518-1525, May 2020.

[23] S. N. Wan Hassan, W.A.S., Ariffin, A., Ahmad, F., Sharberi, S.N.M., Nor Azizi, M. I., Zulkiflee, "COVID-19 Pandemic: Langkawi Vocational College Student Challenge in Using Google Classroom for Teaching and Learning (T\&L)," International Journal of Advanced Trends in Computer Science and Engineering, vol. 9, pp. 3299-3307, May 2020. 